\title{
Controversy
}

\section{Wheezy bronchitis revisited}

\author{
N M WILSON
}

\section{Royal Postgraduate Medical School, Hammersmith Hospital, London}

The description of wheezing illness in preschool children has always been confused. Terms such as wheezy bronchitis, wheeze associated respiratory illness, and asthmatoid bronchitis have been used in the past to describe episodic wheeze in infants and young children. These terms arose because it was felt by paediatricians that episodic wheeze in this age group had a more benign prognosis than asthma of older children. More recently, the use of the term asthma has been advocated to describe all wheezing illness in children, allowing no distinction between virus induced wheeze and other varieties of asthma. ${ }^{12}$

The reason for this is twofold. Firstly, in a cohort study of Australian children, ${ }^{1}$ those who were said to wheeze only in relation to viral infections (labelled wheezy bronchitis) and those who were said to have asthma because of additional precipitating factors, both differed from the control population in terms of several atopic markers. As both wheezing groups also shared several clinical features, it was concluded that they arose from the same population and that the only difference between them was severity. Another factor that led to the abandonment of terms such as wheezy bronchitis was the clear demonstration that asthma was both underdiagnosed and inappropriately treated. ${ }^{34}$ The use of terms such as wheezy bronchitis was in part held to be responsible. ${ }^{34}$ Therefore, in recent years patterns of wheeze and their relationship to viral infections have seldom been defined, in either epidemiological or therapeutic studies. This practice has resulted in a loss of pathophysiological precision which may have implications that are not purely academic.

In the current issue of this journal, Clifford et al reporting their survey of children of 7 and 11 years, ${ }^{5-7}$ return to the possibility that in some, recurrent respiratory symptoms could be related not to atopy but viral infections. ${ }^{7}$ Unfortunately, despite their aim of exploring the inter-relationship of respiratory symptoms in children, they omitted to ask about the association of symptoms and viral infections.
In this article the justification for, and the implications of, classifying the syndrome of asthma in terms of clinical patterns and the response to viral infections will be presented. For want of a better term and for brevity, 'wheezy bronchitis' will be used to mean wheeze triggered by a viral infection, although it is acknowledged that this may not involve a bronchitic element. 'Asthma' will denote reversible wheezing precipitated by a number of other factors in addition to viral infections.

\section{The natural history of asthma}

Does the natural history of wheezing disorders in childhood provide evidence that such illnesses should all be labelled asthma without qualification? The pattern of wheeze in childhood, broadly speaking, can be divided into acute episodes and milder chronic symptoms.

Acute episodes, particularly in younger children, are generally considered to be induced by virus infections as they are often associated with fever and rhinitis. Viruses have been isolated in up to $42 \%$ of acute wheezing episodes. ${ }^{8}$ Technical difficulties in viral isolation are likely to account for most of the negative results, as in one general practice survey the viral isolation rate was the same $(26 \%)$ in wheezy bronchitis as in children with overt colds. ${ }^{9}$ Typically, these acute attacks are recurrent but the frequency may vary from a single episode to repeated attacks every few weeks. There are often long symptom free periods between the acute episodes. ${ }^{1}$ The attacks tend to decrease with age both in number and severity.

On the other hand, chronic symptoms characterised by cough and wheeze particularly at night or on exercise, unrelated to viral infections, tend to increase with age from about the age of 3 years, although they can begin earlier, and in most children symptoms have declined by puberty. These two patterns could be explained in a single population of children by frequent viral infections leading to acute 
attacks in younger children, with an IgE response to aero-allergens, which increases with age, ${ }^{10}$ being responsible for 'allergic' asthma typical of older children. But most infants with episodic wheeze stop wheezing in early childhood, ${ }^{10-13}$ and the prevalence of episodic wheeze has been estimated as being at least three times that of more persistent symptoms. ${ }^{12}$ This could suggest that there are two populations of wheezers. Williams and McNichol, in their influential study of a population cohort of children, were unable to show any subgroups of wheezers when children were assessed between the ages of 7 and 10 years. ${ }^{1}$ There are, however, possible explanations for their conclusions which are relevant to the whole debate.

Firstly, children with atopic asthma may also wheeze with viral infections. Secondly, children with wheezy bronchitis may experience nocturnal, emotional, and exercise induced symptoms, but by definition, only in association with viral infections. This could result in a failure to recognise that the precipitating factor was a viral infection. Thirdly, the children in this cohort were first seen at 7 years, an age by which many would have ceased to have episodes of wheezy bronchitis. ${ }^{13}$

Subsequent epidemiological studies have often failed to explore the relationship of wheezing to viral infections, ${ }^{5-7} 1114$ and some have attempted to explain away findings which have suggested a subpopulation of children with wheezy bronchitis. ${ }^{11}$

The papers by Clifford $e t$ al in the current issue have, at first sight, a bearing on the subject. They found that more 11 year olds were atopic but experienced less cough and non-atopic wheeze than 7 year olds. It is tempting to interpret these findings as evidence for a decline in wheezy bronchitis with age. It must be remembered, however, that Clifford et al compared cross sectional data at two ages and inferred age related changes. As the two populations are not necessarily comparable and there are indications that secular changes in the diagnosis or prevalence of asthma have occurred during this period, ${ }^{15}$ their conclusions are not necessarily valid. They also showed an apparent decline in the cumulative prevalence of wheeze between 7 and 11 years in boys, again raising concern about the essentially cross sectional nature of the data. Nevertheless, their data are compatible with the existence in younger children of a subset with non-atopic asthma.

There is therefore some epidemiological evidence that wheezy bronchitis represents a definite subset of wheezing disease, as most children with episodic symptoms cease wheezing in early childhood and do not develop asthma. The two categories are not exclusive, however, as a proportion of children who have wheezy bronchitis in infancy will develop asthma as they grow older.

\section{Bronchiolitis, wheezy bronchitis, and the development of asthma}

Despite disfavour with the term wheezy bronchitis, clinicians have been reluctant to apply the term asthma to wheezing illness in children under 2 years. The lack of another acceptable diagnosis has led to a rather loose use of the term bronchiolitis to describe a range of disorders from a proved infection with respiratory syncytial virus in infants under 6 months to any wheezing condition in children under 2 years. ${ }^{16}$ Bronchiolitis has characteristic features in severely affected young infants but in many cases it merges imperceptibly into wheezy bronchitis. ${ }^{17}$ No rigid criteria have been established to separate the two conditions for epidemiological purposes. Respiratory syncytial virus infection cannot be considered the distinguishing feature as although most cases of bronchiolitis are due to respiratory syncytial virus infection, most respiratory syncytial virus infections do not result in bronchiolitis. ${ }^{17}$

The association between recurrent wheeze and bronchiolitis has often been described, ${ }^{18}$ but despite numerous follow up studies the association between bronchiolitis and atopic asthma remains controversial. ${ }^{18}$ Many children with atopic asthma experience wheezy bronchitis as infants so it could be said that the inexact criteria used to make the original diagnosis of bronchiolitis in follow up studies could have led to a spurious association between bronchiolitis and atopy. So what is the nature of recurrent post bronchiolitic wheezing? Unfortunately the pattern of wheezing after bronchiolitis has seldom been described in detail. Pullan and Hey found that the excess wheeze after hospital admission for bronchiolitis occurred in the first 4 years of life and was associated with little increase in atopy, and only marginal increase in bronchial responsiveness when assessed at the age of 10 years. ${ }^{19}$ They suggest that 'a history of respiratory syncytial virus lower respiratory tract infection in infancy is associated with an excess of wheezy bronchitis but no increase in asthma'. This conclusion was then dismissed as the authors did not believe that it was valid to make a distinction between wheezy bronchitis and asthma. In a subsequent discussion of this study Pullan's summary of post bronchiolitic wheezing fits well with the present definition of wheezy bronchitis. ${ }^{20}$

It would seem logical therefore to consider that wheezy bronchitis and post bronchiolitic wheezing are part of the same clinical condition, namely that of a particular susceptibility to wheeze in association 
with viral infections. Bronchiolitis could merely be an early manifestation of this tendency. In order to show that bronchiolitis plays a causal role in either wheezy bronchitis or asthma it would be necessary to show that these conditions are increased in population cohorts of older children who were aged under 6 months during epidemics of respiratory syncytial virus. There is as yet no direct evidence that airway inflammation due to early viral infections leads to a predisposition to atopy in man, although observations from in vitro and animal studies suggest that there could be a causal link. ${ }^{21}$

\section{Atopy, increased bronchial responsiveness, and wheezy bronchitis}

Atopy and increased bronchial responsiveness are the two markers often found to be associated with asthma in the childhood population. Neither the possession of atopy nor bronchial hyper-responsiveness alone can explain the predisposition to wheeze, as both are found in significant numbers of children who have never had a lower respiratory illness. ${ }^{22}$

The hypothesis presented here is that there are three independent variables-viral responsiveness (an increased susceptibility to symptomatic viral infections), bronchial responsiveness, and atopic hypersensitivity-which determine the predisposition to wheeze in childhood (figure). In different combinations these interact to give rise to different

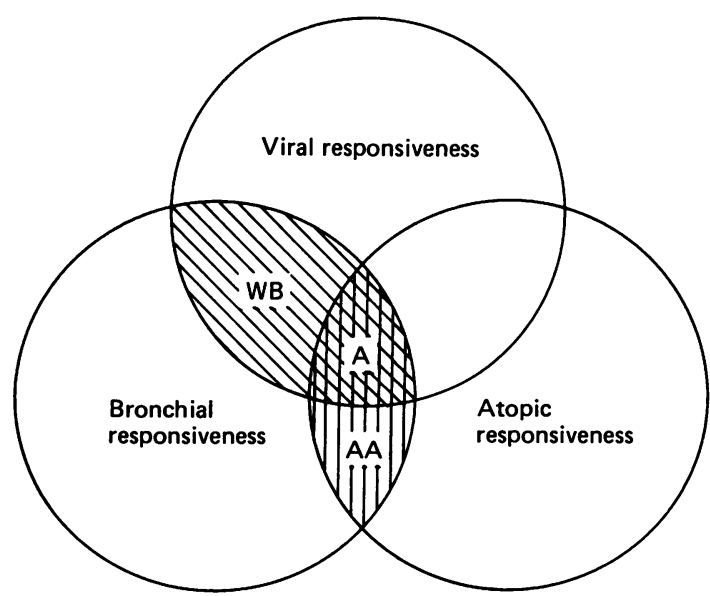

Figure Representation of the hypothetical interaction of three factors that results in wheezing disorders in children. A dynamic inter-relationship exists between the three factors and the expression of each may vary with age and be modified by other host and environmental conditions. $W B=$ wheezy bronchitis, $A A=$ atopic asthma, $A=$ asthma precipitated by both viruses and allergens. wheezing syndromes. The presence of viral responsiveness and increased bronchial responsiveness leads to the condition of wheezy bronchitis; the association of atopy and increased bronchial responsiveness result in allergic asthma-for example, pollen asthma. If all three are present in the same individual then the syndrome of acute viral exacerbations on the background of chronic asthma occurs. This concept of course must be an over simplification as there is likely to be a dynamic interplay between these factors, for example between allergen exposure, atopy, and the degree of bronchial responsiveness. ${ }^{23}$ Possibly recurrent viral infections can alter the level of bronchial responsiveness and enhance IgE sensitisation. ${ }^{21}$ The pattern of clinical symptoms in an individual would depend on the expression of each factor at a given time. This in turn could vary with age, allergen load, environmental conditions, and level of viral immunity.

So if wheezy bronchitis is to be considered as a separate entity, it must be shown that a subgroup of children wheeze only in response to viral infections who have little or no atopy compared with children with asthma of the same age. Australian ${ }^{1}$ and British $^{24}$ studies have compared the prevalence of atopy in wheezy bronchitis and asthma. In both the skin test positivity rate in those with wheezy bronchitis was intermediate between non-wheezing children and those with asthma. In both studies classification took place rather young for all potential cases of childhood asthma to be clinically identified. In addition, the full potential of the wheezy bronchitis group to have become atopic with increasing age was not assessed in the British study. ${ }^{24}$ The Australian cohort was reassessed at 14 years, ${ }^{25}$ but by this time the method of classification had changed and a retrospective review of those with wheezy bronchitis was not possible. Almost all children in the cohort who had ever wheezed, however, were said to have at least one laboratory indicator of allergy but these included eosinophilia and total serum IgE for which a discriminant value with which to distinguish asthma from asymptomatic controls could not be found. In many children the detection of atopy occurred many years after wheezing ceased. Persistent more severe asthma was said to be associated with allergic manifestations at a younger age.

The límited data so far available are compatible with the theory that those described as having wheezy bronchitis on clinical grounds have less atopy, or develop evidence for it later, than those diagnosed as asthmatic. Distinction between the groups must be made retrospectively in older children as laboratory detection of specific IgE precedes atopic symptoms. ${ }^{10}$ Atopic symptoms 
generally increase with age throughout childhood but wheezy bronchitis is characteristically a condition of yonger children.

Recent studies have shown that bronchial responsiveness is increased in most atopic children with asthma, ${ }^{72}$ and this results in symptoms after exposure to a number of agents. However, the association between wheezy bronchitis and bronchial responsiveness is not clear. Clinical observations suggest that many children experience exercise induced symptoms during attacks of wheezy bronchitis but not between acute episodes. Young children with recent symptoms of wheezy bronchitis had increased exercise lability. ${ }^{26}$ In a comparative study Horn and Gregg found the number of children with wheezy bronchitis who had exercise induced bronchoconstriction $(16 \%)$ to be far less than those with asthma $(76 \%)$ but greater than controls $(0 \%) .{ }^{27}$ The results of retrospective studies of older children with a history of viral respiratory illness in infancy have varied with some finding increased bronchial responsiveness, which was independent of a family or personal history of atopy, even in those who were asymptomatic. ${ }^{28}$ This has not been confirmed by others. $^{29}$

Even though the children were as old as 7 and 11 years, the findings of Clifford et al $^{5-7}$ to some extent support the hypothesis that the interaction of three factors determines the clinical pattern of wheeze (figure). They describe two subgroups of children; one was 'a discrete entity' characterised by wheeze, which was strongly related to atopy and increased bronchial responsiveness. ${ }^{7}$ Wheeze was unrelated to atopy in the absence of bronchial responsiveness and vice versa. In non-atopic children wheeze was independent of bronchial responsiveness, although there was a tendency for respiratory symptoms in general to be related to bronchial responsiveness. The authors themselves conclude that their findings could indicate a difference between atopic wheezers and those whose respiratory symptoms are related to viral infections, in whom bronchial responsiveness might be variable. Cough without wheeze could be an indicator of viral responsiveness in the absence of bronchial hyper-responsiveness.

It is likely that in some children the level of bronchial responsiveness varies, increasing during symptomatic periods. Until prospective studies in an infant population are performed it will not be known for certain whether a degree of bronchial hyperresponsiveness is a prerequisite for the development of wheezy bronchitis or asthma. Neither is it clear whether the exercise lability noted in some young children with wheezy bronchitis ${ }^{26}$ is a predictor of later asthma as follow up studies have not been reported.

\section{Familial factors in wheezy bronchitis}

Is there any evidence from family studies of a genetic basis to the predisposition to wheeze in association with viral infections, which could lend support to this as a clinical entity? The evidence should be sought by comparing the family histories of those who wheeze only with viral infections, with families of those who never wheeze with viruses (which would exclude many asthmatics). Previous comparisons between the families of those with wheezy bronchitis and asthma have been confusing in this respect. For example, in the family study of König and Godfrey wheezy bronchitis was defined simply as recurrent wheeze occurring under 4 years of age. ${ }^{30}$ In the study of Sibbald et al, the wheezy bronchitis children were younger than the asthma group and some might have later developed asthma. ${ }^{24}$ It is likely that many of their asthma group also wheezed with viruses. Not surprisingly, they failed to show wheezy bronchitis as a separately inherited entity. They did, however, find that the prevalence of wheezy bronchitis was higher in the relatives of non-atopic wheezers from either group than in the relatives of atopic children. They therefore suggested that 'the reduced predisposition to asthma of many wheezy bronchitis children may result from their failure to inherit a predisposition to atopy'. This observation is compatible with the finding of Clifford $\mathrm{et} \mathrm{al}^{67}$ and the hypothesis that a predisposition to develop wheezy bronchitis exists and if atopy is additionally present, asthma may develop. The common link could be bronchial hyper-responsiveness which may be lost or reduced in the absence of atopy as the child grows older.

Ronchetti et al suggested that children who wheezed under 5 years of age could be differentiated from those who wheezed over 5 years in terms of their adenosine deaminase phenotype. ${ }^{31}$ From this age related data it was inferred that genotype 2:1 adenosine deaminase was normally represented in virus induced wheezers but was rare among older asthmatic children. It would be interesting to review the correlation between clinical features and adenosine deaminase phenotype using stricter clinical definitions.

The familial basis of a predisposition to wheeze with viral infections has not been adequately studied but available evidence is compatible with the proposition that it could be genetic.

\section{Implications}

EPIDEMIOLOGY

Does it matter whether wheezy bronchitis is accepted as a separate manifestation of asthma? By 
avoiding the term, we have been left with some inconclusive answers to important clinical questions. Without separating virus induced wheeze from other causes of asthma, exacerbating factors that may act on one and not the other could be missed. For example, environmental factors such as parental smoking may influence wheezy bronchitis and not asthma. ${ }^{32}$ Similarly, it is possible that changes in environmental pollution or weather patterns could affect the prevalence of virus infections and the distribution of aeroallergens differently and this could be responsible for the dramatic increase in admission for acute wheeze,$^{153}$ unassociated with an increase in prevalence of asthma in older children. ${ }^{33}$

Reluctance to identify the association of wheeze with viral infection is surprising in view of the renewed interest in the association between the development of atopy and viral infections. Possible mechanisms for virus induced wheeze have recently been well reviewed, ${ }^{21} 3435$ and several different host or environmental factors could be responsible for the development of wheezy bronchitis including an IgE response to viral antigens. ${ }^{21} 34$

\section{THERAPEUTIC}

There is little doubt that wheezing at any age should be treated with adequate doses of bronchodilators and not antibiotics, with additional corticosteroids if the wheezing is severe. Controversy still remains in two important clinical areas. Firstly treatment is least satisfactory in those under 18 months old and this is the age group at greatest risk of viral infections.

The other controversy concerns the efficacy of prophylaxis for recurrent acute episodes associated with viral infections in preschool children. Personal observation suggests that in contrast to older children, this age group responds poorly. There have been suggestions that chronic but not acute symptoms respond to cromoglycate and nebulised beclomethasone,$^{36}{ }^{37}$ so the reason for the disappointing results of prophylactic treatment in asthma trials in the preschool age group could be related to the failure to separate acute from chronic symptoms. Unless clinical trials start to consider the therapeutic efficacy on different patterns of symptoms separately, treatment of asthma in this age group will not be rationalised. Treatment for acute wheeze remains a problem, as clearly shown by the increasing numbers who are admitted to hospital. ${ }^{15}{ }^{33}$ Moreover, unless the characteristic insidious change in the pattern of wheezing from the acute episodes of wheezy bronchitis to the more chronic nocturnal cough and exercise induced symptoms in children who develop asthma are emphasised, many children will go undertreated.

\section{Conclusion}

The rationale for the failure to identify virus induced wheeze in recent studies of asthma questionable and needs re-evaluating. It does not seem very wise to extrapolate uncritically from a study of 7 year old Australian children to preschool asthmatics in the United Kingdom. From the limited data available, episodic wheezing occurring particularly in younger children cannot be completely explained by atopy and bronchial hyperresponsiveness as in older children with asthma. There is clearly a need for careful, prospective studies. In particular, clinical subgroups of wheezy young children should be defined, host and environmental factors looked for, and therapeutic approaches assessed. Perhaps a more appropriate and less emotive term than wheezy bronchitis should be agreed upon ......VAW (virus-associated wheeze) or WAVE (wheeze-associated virus episode)?!

I am grateful to Michael Silverman for helpful criticism of the manuscript and to the Asthma Research Council for financial support.

\section{References}

${ }^{1}$ Williams H, McNichol KN. Prevalence, natural history and relationship of wheezy bronchitis and asthma in children. An epidemiological study. Br Med J 1969;iv:321-5.

2 Lee DA, Winslow NR, Speight ANP, Hey EN. Prevalence and spectrum of asthma in childhood. Br Med J 1983;286:1256-8.

3 Speight ANP. Lee DA, Hey EN. Under-diagnosis and undertreatment of asthma in childhood. Br Med J 1983;286:1253-6.

4 Anderson HR, Cooper JS, Bailey PA, Palmer JC. Influence of morbidity, illness label, and social, family and health service factors on drug treatment of childhood asthma. Lancet 1981 ;ii: 1030-2.

5 Clifford RD, Radford M, Howell JB, Holgate ST. Prevalence of respiratory symptoms among 7 and 11 year old schoolchildren and association with asthma. Arch Dis Child 1989;64:1118-25

6 Clifford RD, Radford M, Howell JB, Holgate ST. Prevalence of atopy and range of bronchial response to methacholine in 7 and 11 year old schoolchildren. Arch Dis Child 1989;64:1126-32.

7 Clifford RD, Howell JB, Radford M, Holgate ST. Association between respiratory symptoms, bronchial response to methacholine, and atopy in two age groups of schoolchildren. Arch Dis Child 1989:64:1133-39.

${ }^{8}$ McIntosh K, Ellis EF, Hoffman LS, et al. The association of viral and bacterial respiratory infections with exacerbations of wheezing in young asthmatic children. J Pediatr 1973;82:578-90.

9 Horn ME, Brain EA, Gregg I, et al. Respiratory viral infection and wheezy bronchitis in childhood. Thorax 1979;34:23-8.

10 Foucard T. A follow-up study of children with asthmatoid bronchitis with skin tests and IgE to common allergens. Acta Paediatr Scand 1984:62:633-44. 
1 Park ES, Golding J, Carswell F, Stewart-Brown S. Preschool wheezing and prognosis at 10. Arch Dis Child 1986;61:642-6.

12 Price J. Asthma in children: diagnosis. Br Med J 1984;288: 1666-8.

${ }^{13}$ Foucard T, Sjoberg O. Prospective 12 year follow-up study of children with wheezy bronchitis. Acta Paediatr Scand 1984;73: 577-83.

${ }^{14}$ Anderson HR, Bailey P, Cooper JS. Palmer JC, West S. Morbidity and school absence caused by asthma and wheezing illness. Arch Dis Child 1983;58:777-84.

15 Anderson HR. Is the prevalence of asthma changing? Arch Dis Child 1989;64:172-5.

${ }^{16}$ McConnochie KM, Roghmann KJ. Bronchiolitis as a possible cause of wheezing in childhood: new evidence. Pediatrics 1984; 74:1-10.

${ }^{17}$ Horn MEC, Brain EA, Gregg I, Yealland SJ, Inglis JM. Respiratory viral infection in childhood. A survey in clinical practice, Roehampton 1967-72. J Hyg (Lond) 1975;74:157-68.

${ }^{18}$ Simpson $\mathrm{H}$, Mok YQ. Outcome of respiratory disease in childhood. In: Milner AD, Martin RJ, eds. Neonatal and pediatric respiratory medicine. London: Butterworth, 1985: 211-35.

19 Pullan CR, Hey EN. Wheezing, asthma and pulmonary dysfunction 10 years after infection with respiratory syncitial virus in infancy. Br Med J 1982;284:1665-9.

${ }^{20}$ Pullan CR. Does bronchiolitis predispose to asthma in childhood asthma? In: Macloed JM, Szefler SJ, ed. Sustained release theophylline. Exerpta Medica, Current Clinical Practice Services 32, 1986:40-8.

21 Busse WW. The relationship between viral infections and onset of allergic disease. Clinical and Experimental Allergy 1989;19:1-9.

${ }^{22}$ Peat JK, Britton WJ, Salome CM, Woolcock AJ. Bronchial hyperresponsiveness in two populations of Australian school children III. Effect of exposure to environmental allergens. Clin Allergy 1987;17:291-300.

23 Durham SR, Lee TH, Shaw RJ, et al. Immunological studies in allergen-induced late phase asthmatic reactions. J Allergy Clin Immunol 1984;74:49-60.

${ }^{24}$ Sibbald B, Horn ME, Gregg I. A family study of the genetic basis of asthma and wheezy bronchitis. Arch Dis Child 1980;55: $354-7$.

${ }^{25} \mathrm{McNichol} \mathrm{KN}$, Williams H. Spectrum of asthma in children II. Allergic components. Br Med J 1973;iv:12-6.
${ }^{26}$ Lenney W, Milner AD. Recurrent wheezing in the preschool child. Arch Dis Child 1978;53:468-73.

27 Horn ME, Gregg I. Role of viral infections and host factors in acute episodes of asthma and chronic bronchitis. Chest 1973;63: 44-8.

${ }^{28}$ Gurwitz D, Covey M, Levison H. Pulmonary function and bronchial reactivity in children after croup. Am Rev Respir Dis 1980;122:95-9.

29 Voter KZ, Henry MM, Stewart PW, Henderson FW. Lower respiratory illness in early childhood and lung function and bronchial reactivity in adolescent males. Am Rev Respir Dis 1988;137:302-7.

${ }^{30}$ König P, Godfrey S. Exercise-induced bronchial lability and atopic status of families of infants with wheezy bronchitis. Arch Dis Child 1973;48:942-6.

31 Ronchetti R, Lucarin N, Lucarelli P, et al. A genetic basis for the heterogenicity of asthma syndrome in pediatric ages: adenosine deaminase phenotype. J Allergy Clin Immunol 1984; 74:81-4.

32 Horwood LR, Fergusson DM, Shannon FT. Social and familial factors in the development of early childhood asthma. Pediatrics 1985;75:859-67.

33 Storr J, Barrell E, Lenney W. Rising asthma admissions and self referral. Arch Dis Child 1988;63:774-9.

34 Welliver RC. Viral infection and obstructive airway disease in early life. Pediatr Clin North Am 1983;3:819-27.

35 Schroeckenstein DC, Busse WW. Viral "bronchitis" in childhood: relationship to asthma and obstructive lung disease. Seminars in Respiratory Infection 1988;3:40-8.

${ }^{36}$ Cogswell JJ, Simpkiss MJ. Nebulised sodium cromoglycate in recurrently wheezy preschool children. Arch Dis Child 1985;60: 736-8.

37 Storr J, Lenney CA, Lenney W. Nebulised beclomethasone dipropionate in preschool asthma. Arch Dis Child 1986;61: 270-3.

Correspondence to Dr NM Wilson, Department of Paediatrics and Neonatal Medicine, Royal Postgraduate Medical School, Hammersmith Hospital, Du Cane Road, London W12 0HS.

See pp 1118-1139. 